Brzóska R., Laprus H., Błasiak A., Solecki W. Anterior shoulder instability. I treat most patients with latarjet. Issue Rehabil. Orthop. Neurophysiol. Sport Promot. 2018;24:91-97. DOI: 10.19271/IRONS-00068-2018-24

\section{ANTERIOR SHOULDER INSTABILITY. I TREAT MOST PATIENTS WITH LATARJET}

Roman Brzóska

Hubert Laprus

Adrian Błasiak

Wojciech Solecki

Department of Orthopedics, St Luke's Hospital, Bielsko-Biała, Poland

\section{SUMMARY}

The authors present the results of treatment the instability of the anterior arm using the Latarjet method based on their own experience.

Keywords: shoulder instability, arthroscopic Latarjet, BLS

Date received: 14th January 2018

Date accepted: 11th February 2018

\section{Introduction and aim}

Treatment of chronic anterior shoulder instability is still debated. The most commonly used arthroscopic Bankart repair technique is characterized by very high risk of failure. Numerous studies proved that around onethird of patients after arthroscopic Bankart repair had recurrence of instability and in group of patients younger than 21 years the risk of failure is much higher and is estimated on more than 50\% (Privitera et al., 2012; Flinkkila et al., 2018). Traditionally after Burkhart's analysis of his failed arthroscopic cases performed in 2000, it is well know that the main risk factor of anterior instability recurrence is glenoid bone loss (GBL) or large engaging Hill-Sachs lesion (Burkhart and De Beer, 2000). In 2000 Burkhart assessed critical threshold for soft tissue procedures GBL on $25 \%$, but it was decreased even to $13.5 \%$ in recent years by Tokish et al(Shaha et al., 2015). Analysis of
NIESTABILNOŚĆ CZĘŚCI PRZEDNIEJ RAMIENIA. LECZYMY WIĘKSZOŚĆ CHORYCH METODĄ LARAJET

Roman Brzóska

Hubert Laprus

Adrian Błasiak

Wojciech Solecki

Klinika Ortopedii, Szpital Świętego Łukasza, Bielsko-Biała, Polska

\section{STRESZCZENIE}

Autorzy przedstawiają wyniki leczenia niestabilności przedniej ramienia metodą Latarjet w oparciu o własne doświadczenia.

Słowa kluczowe: niestabilność ramienia, artroskopia Latarjet, BLS

Data otrzymania: 14 styczeń 2018

Data zaakceptowania: 11 luty 2018

the radiographic findings after first time shoulder dislocations performed by Hovelius showed that glenoid rim lesion occurred in $8 \%$ and Hill-Sachs lesion in $54.9 \%$ of total (Hovelius and Rahme, 2016). Bushnell et alstated that recent literature has identified unrecognized large bony lesions as difficult to diagnose and a primary cause of arthroscopic reconstruction failure for instability, as well as a major cause of recurrent instability. Those authors also mentioned a limited sensitivity in detecting the bony lesions (Bushnell et al., 2008).

Open or arthroscopic Latarjet procedure since many years have shown excellent long term clinical outcome and significantly lower recurrence rate than soft tissue procedures (Bessiere et al., 2014; Metais et al., 2016). Currently numerous of different bony procedures was proposed to to restore GBL, but no one of them provides better results 
than latarjet technique. The authors of this article in daily practice treat patients with anterior shoulder instability either with arthroscopic modified Bankart technique or with arthroscopic Latarjet procedure. This modified Bankart technique relies on augmentation of the damaged anterior wall soft tissues by part of subscapularis muscle and the name of this technique is "between glenohumeral ligaments and subscapularis muscle stabilization" (BLS) (Lafosse et al., 2016). Latarjet procedure is performed by authors arthroscopically according to Lafosse recommendations (Brzóska et al., 2012).

The aim of this study is to compare results of arthroscopic shoulder stabilisation after BLS and Latarjet technique based on own experiences and results after minimum 2 years follow-up. The second goal is to underline the limitations for soft tissue procedures and indicate factors in favor of Latarjet.

\section{Material and methods}

Between 2008 and 2016, 292 patients with anterior shoulder instability were treated with an arthroscopic Latarjet and modified Bankart (BLS) technique by 2 experienced surgeons (R.B, A.B) in one hospital. 142 patients underwent arthroscopic Latarjet procedure and 150 patients were treated with BLS technique. During the observation 68 patients lost in follow up (50 from BLS group and 18 from Latarjet group) and finally 224 patients (100 after BLS and 124 after Latarjet) with minimum 2 years follow-up was assessed and analysed in this study. Patients were assessed either in outpatient clinic or using a questionnaire, which was sent to patient who couldn't visit clinic. Patients were contacted by telephone and letters and all of the patients who did not respond were qualified to lose in follow-up group. For BLS group among 100 assessed cases, there were 74 man and 26 women in mean age 27.5 years [SD 10.3] at the time of surgery. The dominant shoulder was the affected joint in 62 cases. The mean follow-up was 8.9 [SD 29.4] months.
Including criteria for BLS were as follows: anterior instability of the shoulder, minimum 2 years follow-up. Excluding criteria were significant glenoid bone loss, previous soft tissue stabilisation surgery, voluntary instability, severe osteoarthritis of the shoulder, drug-resistant epilepsy, high-active patient with sub-significant glenoid rim lesion. For Latarjet group among 124 cases there were 111 man and 13 woman in mean age 28.6 years [SD 8.0] at the time of surgery. The mean follow-up was 52.7 [SD 19.1] months. Including criteria for arthroscopic Latarjet procedure were as follows: anterior shoulder instability with glenoid bone loss and presence of coracoid process with preserve conjoint tendon. Excluding criterion was voluntary instability. Preoperative radiological assessment included X-ray pictures and 1.5 or 3 Tesla MRI, to analyse presence of osteoarthritis and concomitant pathologies like rotator cuff tears, biceps pathologies, Hill-Sachs lesion or labral injuries was performed in every case. Engaging of HillSachs lesion (lafosse and Boyle, 2010) (Figure 1) was checked during initial arthroscopy and additional remplissage procedure (Yamamoto et al., 2007) was performed as necessary in 29 cases in BLS group and in 6 cases in Latarjet group. In initial clinical examination positive apprehension test at

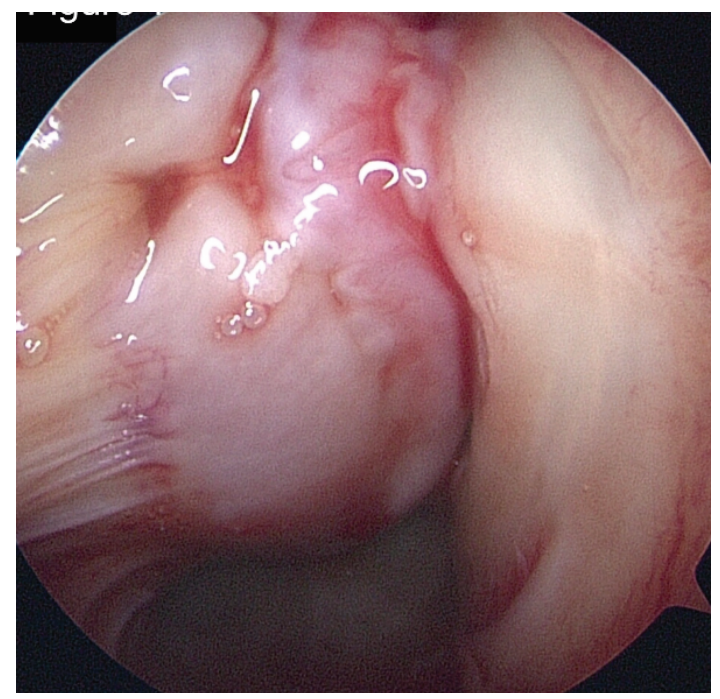

Figure 1. Hill-Sachs lesion engaging the glenoid with defect of its rim.

92 Issues of Rehabilitation, Orthopaedics, Neurophysiology and Sport Promotion - IRONS 
Table 1. Baseline variables of the patients GBL.

\begin{tabular}{|l|l|}
\hline Variable & N \\
\hline Glenoid bone loss group & \\
\hline Group 1 (0-5\%) & 34 \\
\hline Group 2 (5-10\%) & 32 \\
\hline Group 3 (10-15\%) & 24 \\
\hline Group 4 (>15\%) & 10 \\
\hline
\end{tabular}

90 and 140 degrees of abduction was positive in every case.

To better describe the limit of soft tissue procedures patients treated with BLS technique was also separated into 4 groups according to level of glenoid bone loss (Table I). Group 1 consist of patients with GBL $0-5 \%$, in group 2 there were GBL $5-10 \%$, in group 3 there were GBL $10-15 \%$. Last group 4 consist of patients with GBL $>15 \%$.

\section{Results}

Patients from BLS group were evaluated postoperatively at a mean follow-up of 82.9 months [SD 29.4]. For 86 (86\%) patients result was satisfactory with full restoration of joint stability. All of these patients returned to previous level of activities and was satisfied with treatment. Failed of followed method and recurrence of shoulder instability was observed in 14 patients (14\%). In $6(6 \%)$ cases, the reason of recurrence of anterior dislocation was major trauma during sport activity. For group treated with BLS the median of glenoid bone loss for patients with positive result and who failed was $5-10 \%$ and $10-15 \%$ respectively, thus the frequency of failure depended on glenoid bone lesion level what was statistically significant $(\mathrm{p}<0.05)$. In group of patients with glenoid bone damage less than 5\%, there was 1 case who failed after major trauma. In GBL 2nd group (5-10\%), there were 3 failed cases included 2 after trauma. GBL 3rd group consists of patients with glenoid damage that is $10-15 \%$ and in this group 5 failed cases were observed, including 1 posttraumatic case. In the last 4th group, (GBL $>15 \%$ ) there were 5 instability recurrences, including 2 cases of posttraumatic patients. 3 patients who failed underwent revision Latarjet procedure, because of persistent anterior instability and a lot of dislocation episodes. The failure frequency statistically depended on follow-up period as well. For patients who failed, the mean follow up was 115.1 [SD 3.1] months in contrary to 77.7 [SD 28.4] months for patients with positive result. There were no statistically relevant changes after the treatment with procedure in range of external rotation (ER) or internal rotation (IR). It should be underlined that is very meaningful, because techniques basing on subscapularis muscle augmentation typically are burdened with decreasing of range of external rotation. No severe complications, like postoperative infection or early osteoarthritis in observation period, were observed after BLS procedure during observation period.

For Latarjet group evaluated at mean follow-up 52.7 [SD 19.1] months excellent joint stabilization was achieved in 118 from 124 patients $(95.2 \%)$. In 6 cases $(4.8 \%)$ followed treatment weren't completely satisfactory. 3 patients failed after following treatment, but the reason of recurrent dislocation episode was high energetic trauma in every case. For 1 patient who failed, revision Latarjet procedure was performed, because of graft fracture and its further medial displacement. 3 patients had persistent positive apprehension test, but they not required revision surgery. Postoperative complications were observed in 11 cases (8.8\%) after Latarjet procedure. Five patients suffered from persistent anterior pain of the shoulder and required revision arthroscopy and superior screw removal. In $2 / 5$ cases the reason of their persistent pain was partial graft resorption. 1 patient complained from postoperative numbness of operated limb. In this case revision surgery wasn't necessary, because neural symptoms reduced gradually after conservatory treatment. 2 patients reported sensation of friction during full range of motion and in 1 case authors also observed progressive osteoarthritis after operation. There were no significant differences in range of motion after operation 
of total, but in 2 cases remarkable limit of external rotation was observed.

\section{Discussion}

The purpose of this study was to compare efficacy of two arthroscopic shoulder stabilisation techniques: Latarjet procedure with BLS method as modified Bankart technique. The results of this study indicates arthroscopic Latarjet procedure as the most accurate treatment for recurrent shoulder instability with effectiveness $95.2 \%$.

However presented by authors results after own modificated Bankart technique was also satisfactory. After mean follow-up of 82.9 months, regaining of stable shoulder were observed in 86 of 100 (86\%) patients operated by BLS technique apart from age. Thus, BLS technique presented superior effectiveness than arthroscopic Bankart method, leading to risk of failure ranging from $30 \%$ to even more than $50 \%$ for young patients.

No surprisingly the most important factor which play role in failed after BLS was size of GBL. However, the highest rate of failure was observed in the first 2 years after introduction BLS method, when the patients with large glenoid damages were qualified to this procedure. Taking under consideration a patients operated by authors with BLS who had GBL less than 10\% there was only 4/100 (4\%) of failed including 3 after major trauma. The group with the largest defect were the patients with GBL $>15 \%$ or with an intraoperatively observed "flat-line" shaped front wall of the glenoid (Figure 2).

By "flat-line" term, the authors described the bony loss of the antero-medial glenoid resulting in the loss of the anterior curvature and creating a straight vertical cut-off line. The authors believes that this type of glenoid damage predisposes to recurrent dislocations to a similar extent as "inverted pear" described by Burkhart and De Beer (2000) can be a severe risk factor for treatment failure. After 2010 when authors started treat patients with significant GBL by arthroscopic

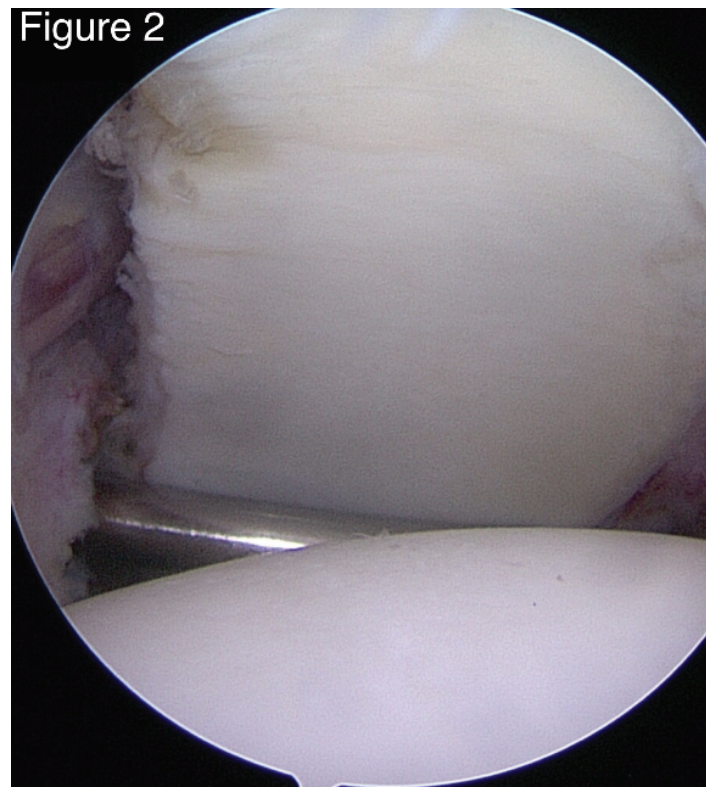

Figure 2. Flat-line shape of glenoid with significant GBL.

Latarjet, the percentage of failed soft tissue procedure decrease substantially. One of including criteria to treatment anterior shoulder instability with Latarjet procedure was presence of GBL. Latarjet as a procedure which restores glenoid surface provides great effectiveness even in case of significant bony defect and its results are less influenced by size of GBL. Radiological analysis after first time dislocation performed by Hovelius and Rahme (2016) showed that more than a half patient had bony lesion on humeral head or glenoid rim after first time shoulder dislocation. In chronic shoulder instability presence of bony lesions is much higher and authors of this article believes that soft tissue procedures shouldn't be first line treatment for patients with chronic anterior instability and with concomitant humeral head or glenoid rim defect, because of its very high risk of failure comparing to bony procedures. Results presented by the authors, in which the failure rate after Latarjet was 6/124 (4.8\%) include 3 after trauma and 3 positive apprehension test without dislocation episode clearly confirm this thesis.

The presence of GBL or Hill-Sachs lesion is not the only risk factor for the recurrence of instability after Bankart procedure. The Instability Severity Index Score (ISIS),

94 Issues of Rehabilitation, Orthopaedics, Neurophysiology and Sport Promotion - IRONS 
described by Balg and Boileau (Purchase et al., 2008), includes of course bone loss of the anteroinferior glenoid and the posterior humeral head as a means of quantifying the risk for failure of an arthroscopic Bankart repair but there are also other factors like type and level of sport or age in time of first dislocation. However the ISIS score has 11 years old and underestimates the factors that are gaining in importance in recent years like sports at the recreational level, which is not a risk factor at ISIS. The widespread fascination of sport goes together with the development of technology, and thus sports such as kitesurfing and carving alpine skiing, makes that even sports on the recreational level carries the higher risk of the severe trauma and the recurrence of instability in consequence. Considering either the above risk factors for failure or the increasing patient's expectations from a treatment effects, qualification to the Latarjet procedure as the treatment of choice in a case of anterior shoulder instability is more and more common in the everyday author's practice.

Unfortunately Latarjet is a demanding technique, with the higher number of intraand postoperative complications comparing to introduce by authors BLS technique. In the material analyzed above, the number of complications after Latarjet was $8 \%$ in comparison with none complication after BLS. In addition, among these $8 \%$ complicated patients there were 3 serious complications like 2 cases of graft lysis and 1 case of transient numbness. However current literature proved that there is no other method of treatment shoulder instability which provides better result than the Latarjet [14] Among short and long term complications of untreated or unsuccessfully treated chronic shoulder instability, there is easy to underline arthropathy progression, worse quality of life and even double than general population mortality rate.

Considering all of the above arguments, effective treatment of anterior shoulder instability should be a priority, and the most effective technique, which is the Latarjet procedure in cases with doubts, should be considered as the method of choice, and not as overtreatment.

\section{Conclusion}

Open or arthoscopic Laterjet procedure is one of the most effective technique for management chronic anterior instability. Contrary to soft tissue procedures like Bankart repair or BLS. It's effectiveness is not diminished by glenoid rim defect. Unfortunately in material presented by authors this demanding technique was burdened the higher risk of postoperative complications. 


\section{REFERENCES}

An VVG, Sivakumar BS, Phan K, Trantalis J. (2016) 'A systematic review and meta-analysis of clinical and patient-reported out-comes following two procedures for recurrent traumatic anterior instability of the shoulder: Latarjet procedure vs. Bankart repair.' J Shoulder Elbow Surg., May;25(5): pp. 853-63.

Balg F, Boileau P. (2007) 'The Instability Severity Index Score: a simple pre-operative score to select patients for arthroscopic or open shoulder stabilisation.' J Bone Joint Surg Br., 89-B(11): pp. 1470-1477.

Bessiere C, Trojani C, Carles M, Mehta SS, Boileau P. (2014) 'The open Latarjet procedure is more reliable in terms of shoulder stability than arthroscopic Bankart repair.' Clin Orthop Relat Res., 472: pp. 2345-2351.

Brzóska R, Blasiak A, Hldaki W, Streit JJ, Toussaint B, Solecki W. (2012) 'Arthroscopic Bankart Repair Using Extracapsular Suture Between the Glenohumeral Ligaments and Subscapularis Tendon (BLS Technique): A Technical Note.' Tech Should Surg., 13: pp. 86-89.

Lafosse L, Boyle S. (2010) 'Arthroscopic Latarjet procedure.' J Shoulder Elbow Surg., 19: pp. 2-12. Burkhart SS, De Beer JF. (2000) 'Traumatic glenohumeral bone defects and their relationship to failure of arthroscopic Bankart repairs: Significance of the inverted-pear glenoid and the humeral engaging Hill-Sachs lesion.' Arthroscopy, 16: pp. 677-94.

Bushnell BD, Creighton RA, Herring MM. (2008) 'Bony instability of the shoulder.' Arthroscopy, 24: pp. 1061-1073.

Flinkkilä T, Knape R, Sirniö K, Ohtonen P, Leppilahti J. (2018) 'Long-term results of arthroscopic Bankart repair: Minimum 10 years of follow-up.' Knee Surg Sports Traumatol Arthrosc., Jan;26(1): pp. 94-99.

Hovelius L., Rahme H. 'Primary anterior dislocation of the shoulder: long - term prognosis at the age of 40 years or younger.' Knee Surgery, Sports Traumatology, Arthroscopy, (Springer Berlin Heidelberg, 2016).

Metais P, Clavert P, Barth J, Boileau P, Broszka R, Nourissat G, Leuzinger J, Walch G, Lafosse L. (2016) 'French Arthroscopic
Society. Preliminary clinical outcomes of Latarjet-Patte coracoid transfer by arthroscopy $v$. open surgery: Prospective multicentre study of 390 cases.' Orthop Traumatol Surg Res., Dec;102(8S): S271-S276.

Privitera DM, Bisson LJ, Marzo JM (2012) 'Minimum 10-year follow-up of arthroscopic intra-articular Bankart repair using bioabsorbable tacks.' Am J Sports Med, 40: pp. 100-107. Purchase RJ, Wolf EM, Hobgood ER, Pollock ME, Smalley CC. (2008) 'Hill-Sachs «remplissage»: an arthroscopic solution for the engaging hill-sachs lesion." Arthroscopy, Jun;24(6): pp. 723-6.

Shaha JS , Cook JB , Song DJ , Rowles DJ, Bottoni CR, Shaha SH, Tokish JM. (2015) 'Redefining "Critical" Bone Loss in Shoulder Instability: Functional Outcomes Worsen With Subcritical Bone Loss.' Am J Sports Med., Jul;43(7): pp. 1719-25.

Yamamoto $\mathrm{N}$, Itoi $\mathrm{E}$, Abe $\mathrm{H}$, Minagawa $\mathrm{H}$, Seki N, Shimada Y, Okada K. (2007) 'Contact between the glenoid and the humeral head in abduction, external rotation, and horizontal extension: a new concept of glenoid track.' J Shoulder Elbow Surg., Sep-Oct; 16(5): pp. 649-56.

96 Issues of Rehabilitation, Orthopaedics, Neurophysiology and Sport Promotion - IRONS 
Authors reported no source of funding. Authors declared no conflict of interest.

Author responsible for correspondence: Roman Brzóska

Department of Orthopedics

St Luke's Hospital

43-300 Bielsko-Biała

Bystrzańska 94B

Poland

brzoska@lukasza.pl
Autorzy nie zgłosili źródła finansowania.

Autorzy nie deklarowali konfliktu interesów.

Autor odpowiedzialny za korespondencję:

Roman Brzóska

Klinika Ortopedii

Szpital Św. Łukasza

43-300 Bielsko-Biała

ul. Bystrzańska 94B

Polska

brzoska@lukasza.pl 